\title{
An autosomal dominant form of hereditary hypotrichosis simplex maps to 18p11.32-p11.23 in an Italian family
}

\author{
Alessandra Baumer ${ }^{1}$, Serena Belli ${ }^{2}$, Ralph $M$ Trüeb $^{3}$ and Albert Schinzel ${ }^{1}$ \\ ${ }^{1}$ Institute of M edical Genetics, University of Zurich, Switzerland; ${ }^{2}$ Consultorio Genetico, Trento, Italy; ${ }^{3}$ Department \\ of Dermatology, University of Zurich, Switzerland
}

We report on a three-generation Italian family with dominant transmission of a form of hereditary hypotrichosis simplex (HHS). The nine affected adults presented with sparse, thin and short hair. Somewhat less sparse and longer hair was observed in the two affected young children in the third generation. Reduced hair growth affected the scalp and body, although normal eyelashes, eyebrows and growth of men's beards were observed. No associated abnormality was detected and the overall psychomotor development of the affected individuals was normal. A phenotypic variation was observed amongst the family members and is suggestive of a reduced penetrance of the trait or the effect of a modifying factor. After exclusion, in our family, of linkage to loci previously described in other forms of atrichia or hypotrichosis, we performed a genome-wide linkage analysis, which resulted in a positive lod score at 18p11.32-p11.23. We defined a critical region of about $35 \mathrm{cM}$ flanked by markers D18S853 and D18S40. The highest two-point lod score was obtained with the microsatellite markers D18S1376, D18S53 and D18S453 (lod score of 3.31 at $\theta=0.00)$. The 18p11.32-p11.23 locus represents the first chromosome region shown to be associated with hereditary hypotrichosis simplex. European Journal of Human Genetics (2000) 8, 443-448.

Keywords: hereditary hypotrichosis simplex; isolated hair abnormality; autosomal dominant; Chromosome locus 18p11.32-p11.23

\begin{abstract}
Introduction
Many conditions involving hair abnormalities have been described to date. Hereditary and congenital hypotrichosis and atrichia are among the most complex areas of disorders of hair growth with several apparently distinctive entities. Numerous cases have been described sharing the features of decreased numbers of hair follicles, small follicles and/or fragile abnormal hairs. This may occur as an isolated defect, or as a feature of an hereditary syndrome, usually in association with other ectodermal defects (ectodermal dysplasia). Where a structural hair shaft defect is characteristic, this has given its name to the disorder, as in monilethrix (MIM 252200). Abnormal features which are often associated with hair loss include dysplastic or brittle fingernails, skin
\end{abstract}

Correspondence: Alessandra Baumer PhD, Institute of Medical Genetics, University of Zurich, Raemistr. 74, $\mathrm{CH}-8001$ Zurich, Switzerland. Tel: +411634 25 36; Fax: +41 163449 16; E-mail: baumer@medgen.unizh.ch Received 28 March 2000; revised 5 April 2000; accepted 5 April 2000 and tooth defects, mental retardation, seizures or other abnormalities (for an extensive list see Online Mendelian Inheritance in $\mathrm{Man}$ ). Dominant, recessive and $\mathrm{X}$-linked transmission of syndromes featuring atrichia or hypotrichosis have been described, whereby recessive inheritance is the most frequently observed mode of transmission ${ }^{1-5}$ and isolated forms of hair abnormalities represent the minority of cases. $^{1,6,7}$

Despite published accounts of literally hundreds of Mendelian hair-growth disorders, the defective genes have been identified only in a few so far. These include anhidrotic ectodermal dysplasia (MIM 305100; ${ }^{3}$ MIM 224900 ${ }^{8}$ ), monilethrix (MIM $252200^{9,10}$ ), autosomal recessive congenital universal atrichia (MIM 203655 $2,7,11,12$ ), and congenital atrichia with severefunctional T-cell immunodeficiency and nail dystrophy (MIM 601705 $5^{13}$ ).

Unlike congenital atrichia that is characterised by total and permanent absence of hair, hair is diffusely thinned, but 
present in hereditary hypotrichosis. Among the hereditary forms of isolated hypotrichosis, Marie Unna's hereditary hypotrichosis (MIM 146550) is the best characterised, and is distinguished from hereditary hypotrichosis simplex (HHS, MIM 146520) by the presence of a twisting hair dystrophy, the reason for which 'hereditary trichodysplasia' has been proposed as an alternative denomination of this disorder. ${ }^{14}$ HSS is a descriptive term for the clinical expression of a variety of phenomena related to diffuse thinning of the scalp hair without any gross abnormality of the hair shaft morphology or associated anomalies. Several HSS pedigrees have been published showing autosomal dominant inheritance (eg MIM 146550, MIM 146520), others show autosomal recessive inheritance (eg MIM 241900), whereby variability is observed in the clinical features, such as the age of onset, severity, and involvement of eyebrows and lashes. ${ }^{15,16}$

In this report we describe a family with a form of hereditary hypotrichosis simplex of the scal p with autosomal dominant inheritance. The genetic locus described in this study represents the first known locus associated with HHS. Future efforts will be directed at investigating candidate genes for mutations underlying this isolated form of hair abnormality.

\section{Subjects and methods Subjects}

The pedigree of the non-consanguineous Italian family is shown in Figure 1. The hair abnormality was first manifested in individual I.1, who was the only affected sibling in a family with 11 children. The affected adults presented with thin, sparse and short scalp hair. The hair growth is particularly sparse at the top of the head, somewhat denser hair growth is observed at the temples. A thin and sparse re-growth of the scalp hair is observed after cutting. The affected men trim their hair every 2 to 3 months. Body hair is present, although it is also sparse. The growth of eyebrows, eyelashes, and men's beards is normal. All affected men shave their beards regularly. The finger and toe nails, which are also trimmed regularly, teeth, skin and sweating are normal. The first dentition in the two affected children in the third generation occurred at about 5 months. The affected members, apart from III.4, showed no further abnormal feature and were of normal intelligence, normal growth and development. In addition to the hair abnormality, individual III.4 was found to have the following abnormal karyotype: $45, X / 46, X, r(X)(p 22.3 q 24$ ?) (data not shown).

Reduced hair growth was evident in all affected individuals from early childhood, with progression over the years and persistent growth of sparse and fine hair in adulthood. Slight phenotypic differences were noticed amongst the family members: individualsII.2 and II.11 were particularly affected by reduced hair growth, whereas siblings III.4 (currently 5 years old, Figure 2a) and 111.5 (currently 2 years old,
Figure 2b) appear to have more and longer hair than their mother (II.7) had in her childhood.

Examination of hair by light and polarisation microscopy did not show any specific changes or gross abnormality of the hair shaft morphology in individual II.7 and her two daughters III.4 and III.5.

\section{Molecular analyses}

DNA was extracted by standard procedures from blood samples of the family members. The blood samples were drawn after obtaining informed consent from the adults and the parents of the children. Haplotype analysis was carried out using microsatellite primers purchased from Research Genetics ${ }^{\circledR}$ (Huntsville, AL, USA). The linkage maps provided by Généthon, GDB, LDB and the Marshfield Medical Research Foundation were consulted for the localisation and the genetic distances of the markers. The microsatellite markers were used in polymerase chain reactions (PCR) consisting of 35 cycles of: denaturation for $30 \mathrm{~s}$ ( $3 \mathrm{~min}$ to the first cycle) at $94^{\circ} \mathrm{C}$, primer anneal ing at $52-60^{\circ} \mathrm{C}$ for $45 \mathrm{~s}$ and primer extension at $72^{\circ} \mathrm{C}$ for $1 \mathrm{~min}$. The reactions were carried out using a Perkin Elmer PCR cycler. The PCR products were separated on $6 \%$ denaturing polyacrylamide gels and visualised by silver staining using standard procedures.

Haplotype and linkage analyses were carried out using the software programs 'Cyrillic ${ }^{\circledR}$ ' and 'Linkage ${ }^{\circledR}$ ' (version 5.1 with Fastlink 3.0P). For the linkage calculations full penetrance of an autosomal dominant trait was assumed with a disease gene frequency of 0.0001 and an equal recombination frequency for females and males. The two-point lod scores were calculated by use of the MLINK program. Allele frequencies were calculated based on the values reported in the Généthon database.

\section{Results}

Haplotype analysis at loci associated with other forms of alopecia indicated a distinct genetic defect in our family. The gene loci we initially investigated included 12q13 (keratin genes ${ }^{9,10}$ ) and the locus for the 'hairless' gene at 8p21-p22, ${ }^{7}$ as well as less likely loci such as Xp22.2-p21.2, Xq11-q21.1, Xq28, 2q34-q36, 13q11-q12.1.,17-20 Clear negative twopoint lod scores were obtained for our family at all these regions (data not shown).

A subsequent genome-wide linkage analysis resulted in a significant lod score at 18p11.32-p11.23. We were able to define a critical chromosome region of about $35 \mathrm{cM}$ covering approximately $15 \mathrm{Mb}$ of genomic sequence (LDB and Marshfield M edical Research Foundation linkage maps). The haplotypes obtained for the 15 most informative markers mapping to the critical site are illustrated in Figure 1. The chromosome region, from marker D18S52 to D18S453, showed segregation of the same haplotype in all affected individuals (indicated with a box). The two meiotic crossovers, observed in 


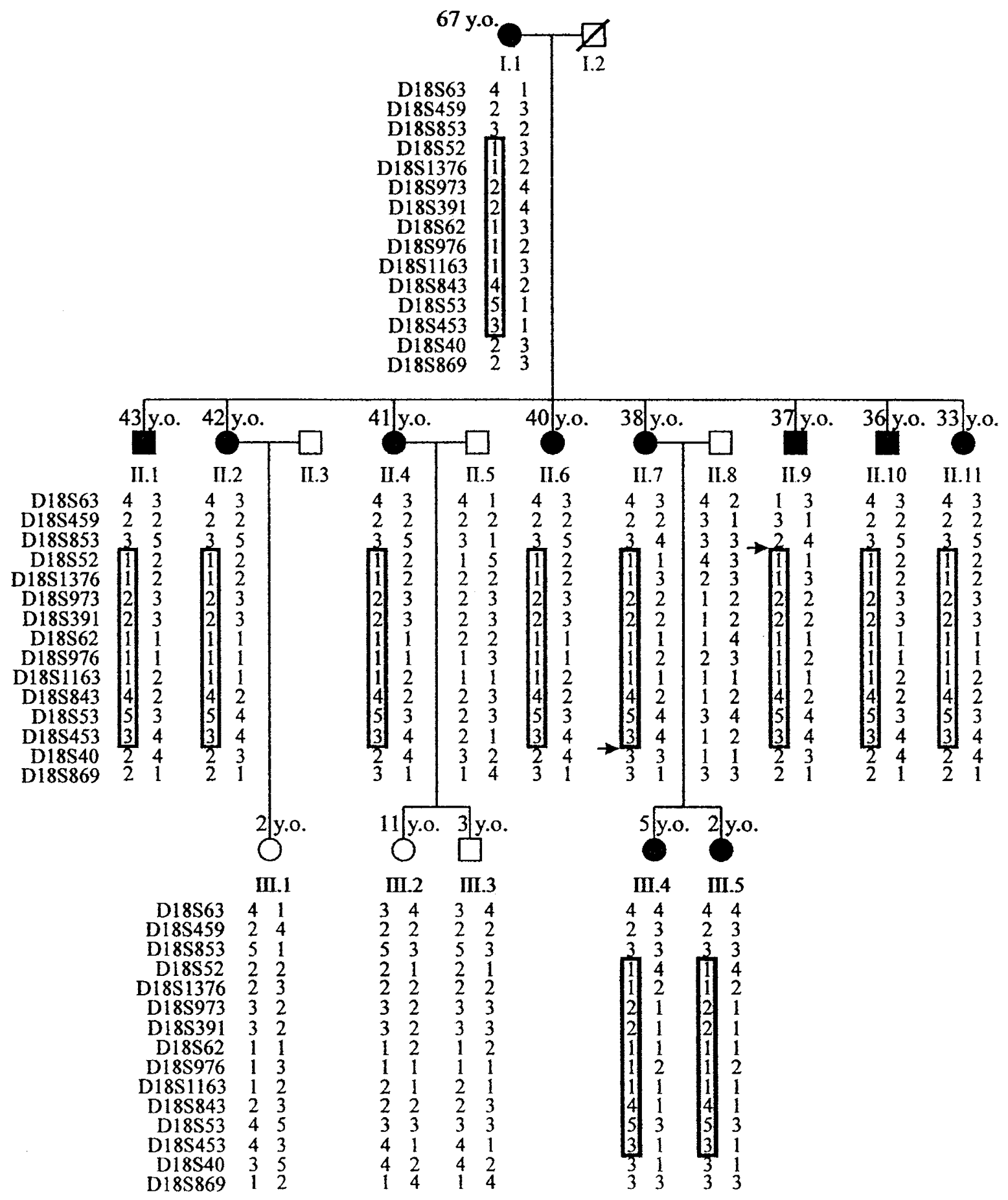

Figure 1 Schematic representation of the family pedigree. Representative results obtained by microsatellite analysis at

18 p11.32-p11.23 are indicated below each individual. The alleles are denoted $1-5$ according to their sizes whereby ' 1 ' indicates the larger allele and ' 5 ' the shortest allele. Indicated in the box is the haplotype at the critical region, shared by all affected individuals.

individualsII.9 and II.7, that define the boundaries of the critical region are indicated with arrows. Table1 summarises the two-point lod scores obtained for a total of 20 markers. A number of further markers which were particularly not informative in our family were not included in the table (eg D18S1267, D18S1261, D18S1210E, D18S981, D18S991, D18S471, D18S344, D18S458, D18S967, D18S1153, D18S71 and further markers flanking the critical region). A two-point 
A

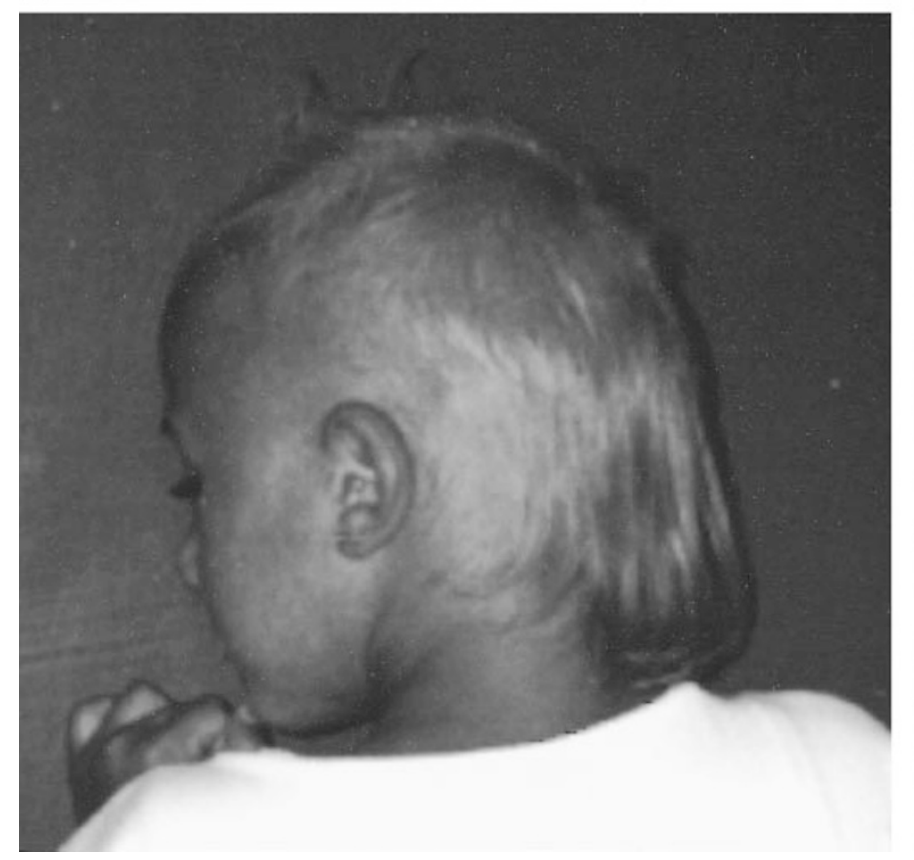

B

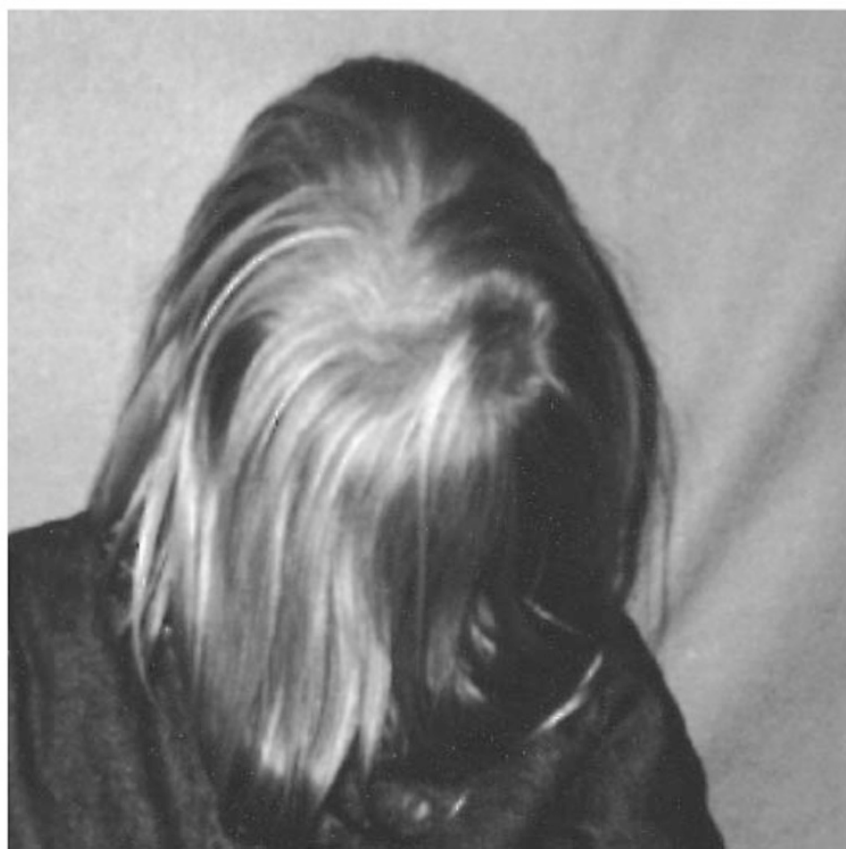

Figure 2 Current photographs of the two affected children. A Individual III.4, aged 5 years; B Individual III.5, aged 2 years, photographed from behind with head tilted backwards.

lod score of at least 3 was obtained for five markers (whereby the maximal theoretical two-point lod score attainable for the family was 3.6 at $\theta=0.00$ ). The best results were obtained with markers D18S1376, D18S53 and D18S453, all of which resulted in a two-point lod score of 3.31 at $\theta=0.00$. The order of the primers, as listed in Table 1, reflects basically that given in the LDB linkage map, the only difference being the inverted order of markers D18S1163 and D18S976. Evidence for a meiotic crossover between the two markers was observed on the paternal chromosome of individual II.2; thus, based on the haplotypes, marker D18S976 appears to map at a position distal to D18S1163.

Table 1 Two-point lod scores obtained for markers at 18p11.32-p11.23

\begin{tabular}{|c|c|c|c|c|c|c|c|}
\hline \multirow[b]{2}{*}{ Markers } & \multicolumn{7}{|c|}{$\Theta$} \\
\hline & 0.00 & 0.01 & 0.05 & 0.1 & 0.2 & 0.3 & 0.4 \\
\hline D18S476 & -infinity & -1.11 & -0.44 & -0.19 & 0.01 & 0.07 & 0.06 \\
\hline D18S1138 & -infinity & -1.11 & -0.44 & -0.19 & 0.01 & 0.07 & 0.06 \\
\hline D18S63 & -infinity & -0.44 & 0.76 & 1.10 & 1.14 & 0.86 & 0.41 \\
\hline D18S1154 & 0.90 & 0.89 & 0.84 & 0.77 & 0.61 & 0.44 & 0.24 \\
\hline D18S459 & -1.30 & 0.67 & 1.20 & 1.29 & 1.13 & 0.79 & 0.35 \\
\hline D18S853 & -0.39 & 1.56 & 2.04 & 2.06 & 1.75 & 1.23 & 0.59 \\
\hline D18S52 & 3.00 & 2.96 & 2.76 & 2.50 & 1.94 & 1.30 & 0.58 \\
\hline D18S1132 & 1.20 & 1.19 & 1.12 & 1.02 & 0.82 & 0.58 & 0.32 \\
\hline D18S1376 & 3.31 & 3.25 & 3.02 & 2.71 & 2.05 & 1.30 & 0.50 \\
\hline D18S973 & 2.40 & 2.36 & 2.20 & 1.99 & 1.53 & 1.01 & 0.43 \\
\hline D18S391 & 2.40 & 2.36 & 2.20 & 1.99 & 1.53 & 1.01 & 0.43 \\
\hline D18S62 & 2.10 & 2.07 & 1.92 & 1.74 & 1.33 & 0.86 & 0.35 \\
\hline D18S976 & 2.10 & 2.06 & 1.90 & 1.69 & 1.24 & 0.74 & 0.25 \\
\hline D18S1163 & 2.70 & 2.66 & 2.48 & 2.25 & 1.73 & 1.16 & 0.50 \\
\hline D18S843 & 3.02 & 2.96 & 2.73 & 2.43 & 1.77 & 1.04 & 0.33 \\
\hline D18S53 & 3.31 & 3.25 & 3.04 & 2.76 & 2.14 & 1.45 & 0.66 \\
\hline D18S40 & -1.00 & 0.97 & 1.48 & 1.55 & 1.34 & 0.94 & 0.43 \\
\hline D18S869 & -0.69 & -0.71 & -0.49 & -0.03 & 0.38 & 0.42 & 0.28 \\
\hline D18S1107 & -1.00 & -0.72 & 0.23 & 0.60 & 0.74 & 0.58 & 0.30 \\
\hline
\end{tabular}

The markers are listed from distal to proximal (from 18p11.32 to 18p11.23)

\section{European Journal of Human Genetics}




\section{Discussion}

We were initially intrigued by the unusual segregation of the disease trait in the non-consanguineous family described in this report. We contemplated the possibility of a de novo mutation followed by loss of heterozygosity at the disease locus in individuall.1, which would have explained the transmission of the dominant trait to all her children. Analysis to this effect was carried out by reconstruction of the parental haplotypes based on the DNA samples of six of the 10 unaffected siblings of individual I.1 (data not shown). However, a conventional linkage analysis, carried out in parallel with samples from the two younger generations, resulted in a significant positive lod score at 18p11.32-p11.23, and thus revealed the purely coincidental transmission of the disease trait to all siblings in the second generation. On the basis of the haplotype analysis at 18p11.32-11.23 of individual I.1 and her siblings we were able to confirm the de novo occurrence of the hypotrichosis (data not shown). The 18p11.32-p11.23 locus described in this study represents the first reported chromosome region associated with autosomal dominant transmission of hereditary hypotrichosis simplex.

\section{Alopecia in cases with chromosomal abnormalities affecting 18p}

A few cases are reported in the literature with alopecia occurring as an associated feature in patients with a chromosome deletion of $18 p .^{21-23}$ In the familial $18 p$ - case described by Uchida and colleagues, ${ }^{21}$ the mother of the 2 -year-old proband presented with alopecia from the age of 2-3years. The hair loss progressed rapidly leading to complete and permanent baldness with in a few months. A similar case has been reported by Jacobsen and Mikkelsen. ${ }^{22}$ The age of onset of the alopecia was at 1 year in their proband; it affected all body hair and also led to complete baldness. A third case was reported by Harris and colleagues ${ }^{23}$ with alopecia in a patient with an 18;21 translocation resulting in an 18p deletion. The $18 p$ deletions were revealed by cytogenetic investigations and their exact breakpoints were not characterised. A further interesting case of reduced and abnormal hair growth was described in a patient with mosaic trisomy $18 .{ }^{24}$ The phenotypic presentation of the alopecia in the three patients with $18 p$ deletions appears to be more severe than in the affected members of our family, and the progression of the hair loss more rapid. On the other hand the hair abnormality in the patient described by Collins and colleagues ${ }^{24}$ appears to be less severe than in our patients.

It is not clear whether the locus at 18p11.32-p11.23 associated with HHS in our family may be involved in the alopecia in the three previously reported 18p deletion cases. $^{21-23}$ Variability of the clinical features could be explained by haploinsufficiency of other genes on 18p, which could aggravate the phenotype associated with the gene underlying HHS in our family.
A slight phenotypic variability is observed among the affected individuals in the family described here, and could be due to incomplete penetrance, the action of a co-dominant trait or modifying factors. Reduced penetrance of dominant traits is reported also for other cases with $\mathrm{HHS}$ and it would clearly be interesting to investigate such families for linkage to the 18p11.32-p11.23 locus. Compared to other reports describing cases with dominant inheritance of HHS it would appear that the age of onset is slightly lower in our family, with an age of onset of about 1-2 years rather than about 5 years. ${ }^{4,6,15,16}$

\section{Genes mutated in other forms of isolated hypotrichosis and atrichia and candidate genes at 18p11.32-p11.23}

Gene loci and genetic defects underlying two forms of isolated alopecia have been characterised to date. A first locus involves a keratin gene cluster on chromosome12q13. Mutations in two hair cortex keratin genes ( $\mathrm{hHbl}$ and $\mathrm{hHb}$ ) localised in the region have been described in patients with the dominant inherited hair disorder monilethrix (MIM 252200 ${ }^{9,10}$ ). The second locus maps to $8 p 21-p 22^{7}$ and gene mutations in the human 'hairless' gene have been found in patients with the recessive transmitted congenital universal atrichia (MIM 203655 $2,7,11,12,25$ ). Interestingly, defects in the human 'hairless' gene appear to be responsible not only for universal atrichia but also for an atrichia with papular lesions (APL). ${ }^{26}$ The 'hairless' gene is thought to encode a multifunctional transcription factor. A highly conserved C-terminal region has been postulated to be involved in the regulation of the thyroid hormone receptor activity.

The $35 \mathrm{cM}$ critical region at 18p11.32-p11.23 associated with HHS in our family contains a number of characterised genes and a number of expressed sequence tags. The known genes include: TGIF, ZF161, LAM A 1, PTPRM, DYT7, NDUFV2, MC5R, GNAL and PTPN2. While for some genes the function and/or associated abnormal phenotypes are known, little is known in other cases. The gene ZF161 (zinc finger protein 161) has been proposed as a candidate gene for holoprosencephaly type4 (MIM $142946^{27}$ ). DYT7 has been postulated to be involved in idiopathic torsion dystonia. ${ }^{28}$ Disruption of the murine MC5R (melanocortin 5 receptor) gene was shown to result in animals with defective exocrine gland function. ${ }^{29}$ GNAL (guanine nucleotide-binding protein) appears to be involved in olfaction. ${ }^{23}$ Future efforts will be directed at identifying and investigating candidate genes for HHS in the 18p11.31-p11.23 region.

\section{Acknowledgements}

We wish to thank all members of the family described in this work for their collaboration. The study was in part supported by the Swiss National Science Foundation (grant no. 32-37798.93 to AS). 


\section{References}

1 Anzai $\mathrm{H}$, Shimizu $\mathrm{H}$, Nishikawa T: X-linked recessive inheritance in a family with isolated congenital alopecia. Lancet 1991; 347: 337-338.

2 Cichon S, Anker M, Vogt IR et al: Cloning, genomic organization, alternative transcripts and mutational analysis of the gene responsible for autosomal recessive universal congenital alopecia. Hum Mol Genet 1998; 7: 1671-1679.

3 Kere J, Srivastava AK, Montonen $O$ et al: X-linked anhidrotic (hypohidrotic) ectodermal dysplasia is caused by a mutation in a novel transmembrane protein. Nat Genet 1996; 13: 409-416.

4 Obsen $\mathrm{HH}$, Clemmensen OJ, Brandrup F: Familial hypotrichosis of the scalp. Autosomal dominant inheritance in four generations. Acta Dermato-Venereologica 1991; 71: 349-351.

5 Radhakrishna $U$, Blouin JL, Mehenni $H$ et al: The gene for autosomal dominant hidrotic ectodermal dysplasia (Clouston syndrome) in a large Indian family maps to the 13q11-q12.1 pericentromeric region. Am J Med Genet 1997; 71: 80-86.

6 Just M, Ribera M, Fuente MJ, Bielsa I, Ferrandiz C: Hereditary hypotrichosis simplex. Dermatology 1998; 196: 339-342.

7 Nöthen MM, Cichon S, Vogt IR et al: A gene for universal congenital alopecia maps to chromosome8p21-22. Am J Hum Genet 1998; 62: 386-390.

8 Monreal AW, Ferguson BM, Headon DJ, Street SL, Overbeek PA, Zonana J: Mutations in the human homologue of mouse dl cause autosomal recessive and dominant hypohidrotic ectodermal dysplasia. Nat Genet 1999; 22: 366-369.

9 Winter $H$, Rogers MA, Gebhardt $M$ et al: A new mutation in the typell hair cortex keratin hHbl involved in the inherited hair disorder monilethrix. Hum Genet 1997; 101: 165-169.

10 Winter $H$, Rogers MA, Langbein $L$ et al: Mutations in the hair cortex keratin hHb6 cause the inherited hair disease monilethrix. Nat Genet 1997; 16: 372-374.

11 Ahmad W, Faiyaz ul Haque M, Brancolini V et al: Alopecia universalis associated with a mutation in the human hairless gene. Science 1998; 279: 720-724.

12 Ahmad W, Irvine AD, Lam H et al: A missense mutation in the zinc-finger domain of the human hairless gene underlies congenital atrichia in a family of Irish travellers. Am J Hum Genet 1998; 63: 984-991.

13 Frank J, Pignata C, Panteleyev AA et al: Exposing the human nude phenotype. Nature 1999; 398: 473-474.

14 Solomon LM, Esterly NB, Medenica M: Hereditary trichodysplasia: Maria Unna's hypotrichosis. J Invest Dermatol 1971; 57: 389-400.

15 Toribio J, Quiñones PA: Hereditary hypotrichosis simplex of the scalp. Brit J Dermatol 1974; 91: 687-696.

16 Bentley-Philips B, Grace HJ: Hereditary hypotrichosis. Brit J Dermatol 1979; 101: 331-339.
17 Lubianca Neto JF, Lu L, Eavey RD et al: The Bjornstad syndrome (sensorineural hearing loss and pili torti) disease gene maps to chromosome2q34-36. Am J Hum Genet 1998; 62: 1107-1112.

18 Oosterwijk JC, van Zandvoort P, Nelen M, van Oost B: Linkage analysis and regional assignment of keratosisfollicularis spinulosa decalvans to Xp22.2-p21.2. Cytogenet Cell Genet 1991; 58: 2078.

19 Traupe $H$, van den Ouweland AMW, van Oost BA et al: Fine mapping of the human biglycan (BGN) gene within the Xq28 region employing a hybrid cell panel. Genomics 1992; 13: 481-483.

20 Zonana J, Clarke A, Sarfarazi $M$ et al: X-linked hypohidritic ectodermal dysplasia: localization within the region Xq11-21.1 by linkage analysis and implications for carrier detection and prenatal diagnostics. Am J Hum Genet 1988; 43: 75-85.

21 Uchida IA, MCRae KN, Wang HC, Ray M: Familial short arm deficiency of chromosome 18 concomitant with arhinencephaly and alopecia congenita. Am J Hum Genet 1965; 17: 410-419.

22 Jacobsen P, Mikkelsen $\mathrm{M}$ : The 18p-syndrome. Report of two cases. Ann Genet 1968; 11: 211-216.

23 Harris CJ, Israel JN, Okada LE: 18p- syndrome: an unusual etiology for familial delayed development with mild dysmorphia. Am J Hum Genet 1983; 35: 94A.

24 Collins AL, Fisher J, Crolla JA, Cockwell AE: Further case of trisomy 18 mosaicism with a mild phenotype. Am J Med Genet 1995; 56: 121-122.

25 Zlotogorski A, Ahmad W, Christiano AM: Congenital atrichia in five Arab Palestinian families resulting from a deletion mutation in the human hairless gene. Hum Genet 1998; 103: 400-404.

26 Sprecher E, Bergman R, Szargel R, Friedman-Birnbaum R, Cohen $\mathrm{N}$ : Identification of a genetic defect in the hairless gene in atrichia with papular lesions: evidence for phenotypic heterogeneity among inherited atrichias. Am J Hum Genet 1999; 64: 1323-1329.

27 Sobek-Klocke I, Disque-Kochem C, Ronsiek M et al: The human gene ZFP161 on 18p11.21-pter encodes a putative c-myc repressor and is homologous to murine Zfp161 (chr17) and Zfp161-rs1 (X chr). Genomics 1997; 43: 156-164.

28 Leube B, Hendgen T, Kessler KR, Knapp M, Benecke R, Auburger G: Evidence for DYT7 being a common cause of cervical dystonia (torticollis) in central Europe. Am J Med Genet 1997; 74: 529-532.

29 Chen W, Kelly MA, Opitz-Araya X, Thomas RE, Low MJ, Cone RD: Exocrine gland dysfunction in MC5-R-deficient mice: evidence for coordinated regulation of exocrine gland function by melanocortin peptides. Cell 1997; 91: 789-798.

30 Belluscio L, Gold GH, Nemes A, Axel R: Mice deficient in G(olf) are anosmic. Neuron 1998; 20: 69-81. 